\title{
La media noche y La luz del día: dos obras de Valle- Inclán escritas al hilo de la Primera Guerra Mundial
}

Adolfo Caparrós Gómez de Mercado. Profesor de lengua y literatura

IES Francisco Ayala (Hoyo de Manzanares. Madrid)

Resumen:

Esta nota forma parte de un estudio más extenso en el que se analizan comparativamente las dos obras de Ramón del Valle-Inclán, a la vez que se enmarca su redacción en el contexto histórico y geográfico, ya que las obras tratan el viaje del escritor gallego a Francia, pero fueron escritas en Galicia. El contexto, evidentemente, es el de la Primera Guerra Mundial.

Palabras clave:

Gran Guerra, literatura, periodismo, novela, Francia.

Abstract:

This note belongs to a longer study which compares two works of Ramón del Valle-Inclán, in the historical and geographical context. Both of works tell of the travel of the Galician writer to France, which were written in Galicia. The context, obviously, is the First World War.

Key Words:

Great War, Literature, Journalism, Novel, France. 


\section{Introducción}

Ramón del Valle-Inclán parte a Francia el 21 de febrero de 1916 con el fin de escribir sobre la Gran Guerra: aunque mucho menos estudiado que otros viajes del autor, nos encontramos con uno de los puntos de inflexión en su creatividad, como se verá en estas páginas.

De alguna manera, el viaje es representativo de la nueva mentalidad del escritor: "Pero esa razón de compromiso como hombre social -tan auténticamente conmovido por los terribles acontecimientos- tiene su más significativa plasmación en el viaje a Francia que le gestiona su amigo, traductor y admirador Jacques Chaumié, hijo de un destacado político de la Tercera República, y que Valle cumplirá como corresponsal de El Imparcial (Madrid) y La Nación (Buenos Aires)” (López Casanova, 2000: 160).

Así, nos encontramos con un nuevo retrato de Valle-Inclán. Se ha hablado mucho de su "máscara”, pero consideramos que son diversas, y que van variando según las modas y el estado de ánimo del genial gallego, por lo que sería más preciso hablar de "máscaras": "Claro que este tan decisivo viaje, esta tan excepcional experiencia vital, dinamiza -como no podría ser de otra manera- otra cara de Valle (presente siempre en él), la que corresponde a lo que llamaríamos la mítica del personaje, o lo que es lo mismo, a su atractiva máscara. Una mítica que él motiva ya, y muy vivamente, desde su propia indumentaria, según el apretado retrato que traza Corpus Barga -compañero y confidente- ("Llevaba capote, boina, polainas y una maquila cogida de la muñeca con la correa”), y cuyo aspecto militar, unido, además, a sus barbas y a la falta del brazo, hará -para culminación del signo mistificador- "que algunos soldados [...] le tomaran por le general francés que gozaba de más popularidad, el general Goureaud [...]” (manco también como Valle-Inclán) (López Casanova, 2000: 160-161).

No se debe olvidar la admiración de Ramón María del Valle-Inclán por los militares. Primero, en las declaraciones en las que confiesa su inclinación por dicho mundo, y su decisión final de decantarse por las letras. Por otro, su literatura está plagada de alusiones a las armas. La trilogía carlista (que es su versión de dichas guerras), muchos de sus cuentos como Las Sonatas, y, por supuesto, La media noche y En la luz del día. También se puede citar una obra más moderna, Los cuernos de don Friolera, que en este caso supone una visión esperpéntica y satírica del mundo de la espada. Llama la atención la mentalidad de nuestro protagonista, más pendiente de la estética que del peligro de las balas en primera línea de guerra. Dandi siempre, sean cuales fuere las circunstancias.

Además de su labor como cronista, Valle hace este viaje movido por la idea de escribir un libro bélico que refleje la conmoción producida por la Primera Guerra Mundial: "En tal sentido, no se olvide, al respecto, 
que Valle cumple su viaje como corresponsal (con intención, claro está, de ofrecer una crónica de la guerra) (López Casanova, 2000: 161-162):

“Escribiré un libro que tengo ya visto en concepto (...) Yo tengo un concepto anterior, yo voy a constatar ese concepto y no a inventarlo. El arte es siempre una abstracción (...) La guerra no se puede ver como unas cuantas granadas que caen aquí o allá, ni como unos cuantos muertos y heridos que se cuentan luego en las estadísticas; hay que verla desde una estrella, amigo mío, fuera del tiempo, fuera del tiempo y del espacio".

Bellísimas palabras de Valle-Inclán que recuerdan por momentos su elaboradísimo tratado de estética, $L a$ lámpara maravillosa. Sorprende la poca satisfacción que el propio Valle-Inclán obtiene de La media noche. Se supone que estas palabras, aunque al principio de la obra, debieron escribirse con el libro cerrado:

"Yo, torpe y vano de mí, quise ser centro y tener de la guerra una visión astral, fuera de geometría y de cronología, como si el alma, desencarnada ya, mirase a la tierra desde su estrella. He fracasado en el empeño, mi droga índica en esta ocasión me negó su efluvio maravilloso. Estas páginas que ahora salen a la luz no son más que un balbuceo del ideal soñado. Volveré a Francia y al frente de batalla para acendrar mi emoción, y quién sabe si aún podré realizar aquel orgulloso propósito de escribir las visiones y las emociones de Un día de guerra" (Valle-Inclán, 1976: 774).

Valle-Inclán nunca volvió al frente, ni publicó Un día de guerra. La contienda terminó, y el propio autor gallego dio otra vuelta de tuerca a su estética, que muy poco tuvo ya de místico, de onírico, de estelar. No sorprende tampoco la alusión del autor a "mi droga índica”, ya que por esas fechas la consumía habitualmente, dedicándole el poemario La pipa de Kif. De hecho, su fracaso en el mundo de la política como diputado carlista, tuvo mucho que ver con esas y otras excentricidades más que con los motivos ideológicos. Sirvan como ejemplo el encerrar a su esposa Josefina Blanco para que no representase una obra de Echegaray -su rival dramático-, aunque el tiempo ha puesto a cada uno en su sitio (premios Nobel aparte); aparecer en plena Gran Vía, a principios del siglo XX vestido de mexicano, cuando los caballeros todavía iban con sus capas y sus levitas; o su célebre barba engreñada, que ya le acompañaría como seña de identidad...

\section{La media noche}

Destacamos el arranque de La media noche -que como ya se ha escrito, está fechada en 1916- ya que combina la delicadeza mística de Ramón del Valle-Inclán con la crudeza de la guerra, produciéndose un efecto que hace que el olor a cadáver nos parezca bello: 
"Son las doce de la noche. La luna navega por cielos de claras estrellas, por cielos azules, por cielos nebulosos. Desde los bosques montañeros de la región alsaciana, hasta la costa brava del mar norteño, se acechan dos ejércitos agazapados en los fosos de su atrincheramiento, donde hiede a muerto como en la jaula de las hienas. El francés, hijo de la loba latina, y el bárbaro germano, espurio de toda tradición, están otra vez en guerra. Doscientas leguas alcanza la línea de sus defensas desde los cantiles del mar hasta los montes que dominan la verde plana del Rhin. Son cientos de miles, y solamente los ojos de las estrellas pueden verlos combatir al mismo tiempo, en los dos cabos de esta línea tan larga, a toda hora llena del relampagueo de la pólvora y con el trueno del cañón rodante por su cielo" (Valle-Inclán, 1976: 777).

Esta etapa estética de Valle viene marcada por el dolor de la pérdida de su hijo, casi bebé, en Cambados. En contra de lo que pudiera parecer, más que de una sequía habría que hablar de un florecimiento de obras, y remate de otras atascadas, que además son de una belleza y de una sensibilidad admirables.

El caso recuerda al más actual de Francisco Umbral con Mortal y rosa. Sin mencionar expresamente a su hijo, como hace el autor vallisoletano, Valle-Inclán vacía sus sentimientos en una estética puente, o bisagra, entre el modernismo superado -Rubén Darío ha muerto ese año de 1916- y el esperpento todavía no inventado.

Se puede encontrar un desahogo a ese dolor, que le marcó para toda su vida y que está reflejado en Divinas palabras, Tirano Banderas, en La media noche por primera vez y que sólo puede escribir alguien que haya perdido a un hijo. Con el tiempo, este dolor se va agravando en esperpentos como Tirano Banderas, cuya escena donde se relata la muerte de un niño es estremecedora:

“[...] La pequeña comprende, y, sofocando los sollozos, besa suave, suavemente, la barba del padre. Pero luego torna a suspirar:

-¡Se murió nuestro bebé!

Y comienza la madre:

-¡Se lo llevó Dios! ¡Se lo llevó Dios! ¡Se lo llevó Dios!

Tiene el gesto obstinado, y los ojos secos. Con dos dedos oprime los párpados rígidos de su niño muerto. Los cazadores alpinos desfilan hacia las trincheras, pasan sin verlos, encorvados bajo la borrasca de nieve. Se hunde el techo de una casa, y en las calles desiertas resuena el galope de las vacas perdidas, con el tolón, tolón de los cencerros. El cañoneo terco y lento, no cesa entre las hogueras de Thann y Metzeral” (Valle-Inclán, 1976: 783-784).

No es de extrañar que el posicionamiento de Valle-Inclán -estético-modernista en su primera etapa, si se puede hablar de etapas en una obra donde hay un proceso, pero el autor tiene la personalidad de don 
Ramón- cambiara radicalmente al ver la guerra en primer plano, y también en esto variara su concepción. Cuando se acerca el final de La media noche, el patetismo recuerda ya un poco a su nueva estética esperpéntica, la cita recoge la rendición de las tropas alemanas:

“-¡Franceses! ¡Franceses! ¡Camaradas!

Los que restan ilesos arrojan los fusiles y levantan los brazos:

-¡Camaradas! ¡Camaradas!

Forman grupos sombríos, atónitos, con una torva expresión de desamparo. La derrota los embrutece y envilece:

-¡No somos prusianos! ¡Somos bávaros!

Y otro grupo arrodillado en el fango, con los brazos en alto:

-¡Los bávaros no queríamos la guerra! ¡Franceses! ¡Franceses! ¡Camaradas!

Perdida la esperanza de vencer, ciega como un instinto, ingenua y brutal, parecen bueyes desalentados. Los franceses les conceden cuartel con el gesto de la victoria” (Valle-Inclán, 1976: 807).

\section{Una filosofía bélica}

Hay que destacar que, aunque crónica bélico-trascendental, Valle recurre al elemento clave de la guerra desde el primer momento, es decir, el avión. Veamos cómo refleja la llegada de una escuadrilla:

"Y la luna navega por los cielos de claras estrellas, por cielos azules, por cielos de borrasca. Sobre las doscientas leguas de foso cenagoso, los cohetes abren sus rosas, tiembla la luz de los reflectores, y en la tiniebla del cielo bordonean los aviones que llevan la carga de explosivos para destruir, para incendiar, para matar... Ocupan la carlinga alegres oficiales, locos de vértigo del aire, como los héroes de la tragedia antigua del Vértigo erótico. Vestidos de pieles, con grandes gafas redondas, y redondos cascos de cuero, tienen una forma embrionaria y una evocación oscura de monstruos científicos. Vuelan contra el viento y a favor del viento, les dicen su camino las estrellas" (Valle-Inclán, 1976: 779).

Da una buena idea del estilo metafísico con el que Valle-Inclán quiso relatar la guerra. También de la importancia de los aviones en esta Gran Guerra, que en seguida quedó eclipsada por la de 1939, pero que fue de una magnitud y crueldad tremenda. También nos da una muestra de la importancia y confianza que tenía el mundo del periodismo en un escritor como Ramón María del Valle-Inclán, que en varios momentos renegó del mundo de la rotativa, y que ahora trabajó para él. 
Ya que tanto se ha incidido en la influencia de otros autores, varios de ellos franceses, sobre el escritor gallego, Luis Blanco Vila propone una influencia clarísima de nuestro escritor sobre Antoine de Saint Exupéry, que, además de El principito, atesora una abundante literatura sobre la aviación. Valga la referencia a obras como: Vuelo nocturno (1931), Piloto de guerra (1942) o Correo del sur (1929), obras todas ellas posteriores a las que aquí se estudian, que son de 1916. Veamos el arranque de Vuelo nocturno:

"Las colinas, bajo el avión, cavaban ya su surco de sombra en el oro del atardecer. Las llanuras tornábanse luminosas, pero de una luz inagotable: en este país no cesaban de exhalar su oro, como terminado el invierno, no cesaban de entregar su nieve.

Y el piloto Fabien que, del extremo Sur, conducía a Buenos Aires el correo de la Patagonia, conocía la proximidad de la noche por las mismas señales que las aguas de un puerto: por ese sosiego, por esas ligeras arrugas que dibujaban apenas los tranquilos celajes. Penetraba una rada, inmensa y feliz" (Saint-Exupéry, 1990: 13).

La influencia parece clara, sobre todo en la idea de escribir un libro donde el enfoque principal es desde el aire, donde el protagonista, más que una persona, es una máquina que sirve para ganar guerras y que se cuida como a un caballo, por ejemplo.

La media noche y En la luz del día son dos piezas literarias de calidad excepcional (difíciles de encontrar hasta que han sido incluidas en la Obra completa, editada por Espasa-Calpe en 2002).

Nuevamente, las palabras de Ramón del Valle-Inclán nos deleitan por su exquisitez. Por otro lado, nos sumamos a la opinión de López-Casanova de que estas dos obras son "radicalmente originales", por lo menos no hemos encontrado, en los documentos que se han leído, la más mínima alusión al plagio o la intertextualidad, referencias que sí se encuentran en otros estudios sobre la obra de Valle-Inclán. Sí que encontramos en cambio esta referencia, que incide en lo novedoso y original de los dos escritos:

"En la literatura española Cervantes es uno de esos autores privilegiados: no satisfecho de acuñar en El Quijote la faz de la moderna novela realista, causa por la cual seguimos leyéndolo con fruición, configura en sus entremeses, antes que Molière, la comedia de costumbres o de sátira social. Pues bien, Valle-Inclán se nos antoja émulo de don Miguel en cuanto a creatividad y anticipación. Hoy por hoy (y ya no resulta prematuro afirmar tal cosa) es evidentemente el noventayochista que mejor ha resistido el paso del tiempo. Su teatro se representa en España con tanto éxito, si no más, como el de nuestros más destacados dramaturgos vivos, y su Luces de bohemia nos ha parecido a los espectadores españoles de hoy escrita literalmente hic et nunc" (Villanueva, 1991: 308).

Mucho se ha hablado del célebre vuelo en avión de guerra de Valle-Inclán, por un lado, Darío Villanueva lo considera la clave de las dos obras: 
“Según la información de Corpus Barga esta experiencia aeronáutica, nocturna además, tuvo capital importancia para la construcción de la obra que nos ocupa: 'El vuelo de noche ha sido una revelación -le confesó don Ramón poco antes de partir para Madrid- será el punto de vista de mi novela, la visión estelar’ [...] De su viaje a los frentes de guerra Valle-Inclán no sólo se trajo materia documental y emoción poética, sino también, definitivamente perfilado, el artificio técnico con que plasmar ambas. Así pues, la visión astral tuvo origen en una posición física y real del propio Valle; éste podría haber convertido su experiencia vivida en simple posición literaria del narrador, matizando a su luz la convención existente en todo texto narrativo entre autor y lector; pero fue más allá, y la transmutó en posición mágica, milagrosa del autor, al que se atribuye de esta forma, como dice Matilla, el papel de demiurgo. Y esta mitificación de un hallazgo técnico se apuntala con el párrafo que sigue a la 'Breve noticia' y precede al cuerpo de la narración” (Villanueva, 1991: 312).

Por su parte, Arcadio López-Casanova comentaba en el estrado del Paraninfo de la Universidad de Santiago de Compostela que dada la personalidad imaginativa de Ramón María del Valle-Inclán, el viaje en avión pudiera tratase más de una nueva invención literaria, que de una realidad, circunstancia que hablaría muy a favor de la creatividad e imaginación del genial gallego.

Volviendo a la visión estelar, nos encontramos con la idea de novela o reportaje coral, desarrollada por Darío Villanueva. En La media noche, no hay un protagonista principal, por lo que quizá se piense más en el reportaje que en la novela. El caso es que los reportajes deben tener también un protagonista, ya sea este un presidente de gobierno, un médico, un científico, un escritor... Sin embargo en la obra de Valle-Inclán ocurre un poco, y vuelvo a incidir sobre esto, como en el teatro, donde los personajes pueden no tener nombre: un soldado, el médico, la monja, las hijas.

Darío Villanueva también habla del tratamiento del tiempo; se supone que hay unas jornadas, que no tienen nada que ver con la división de los capítulos, que son más bien como escenas cinematográficas. En esta obra se ve perfectamente la concepción cinematográfica de Valle-Inclán, y en ese sentido también se podría clasificar.

La luz del día supone una culminación mística a los horrores de la guerra, el triunfo del bien sobre el mal, y esa venida victoriosa, no podía ser de otra manera, llega desde los cielos. Como conclusión diremos que tanto La media noche como La luz del día son obras por descubrir, y que consideramos que no se les ha dado la repercusión y el reconocimiento que, honestamente, consideramos merecen. Para finalizar, vamos a ofrecer las bellísimas palabras del inicio de En la luz del día, que nos regalan la vista, nos mecen en ese vuelo nocturno sobre el campo de batalla: 
"El sol del alba da su luz a los horrores de la guerra. Un vasto rumor de voces y de conciencias, más ardiente que el viento del desierto, pasa sobre la dulce y atarazada Francia. Se siente el temblor de las almas como tremolar de gloriosas banderas, y el afán de los corazones tiene en el aire una vibración más pura que la luz. Grandes ejércitos de rubios bárbaros vigilan agazapados en los fosos de su atrincheramiento, y miles de soldados franceses que van por caminos desaparecen en las revueltas, se pierden en las sombra de los bosques, se ocultan al trasponer las lomas. La pequeñez del hombre en el paisaje adquiere la angustia de una verdad desconsoladora y final. Vuelan nubes de humo entre relampagueos y súbitas llamas, el tumulto de la batalla pasa sobre los campos estremecidos y llenos de ecos, con sus aldeas abandonadas, sus puentes rotos, sus granjas en llamas. No se ven los ejércitos y los campos parecen en soledad. Es la guerra sin tropel y la furia, la guerra de una matemática cruel que tiene la ciega voluntad de los astros. Y en la clara turquesa matinal, el vasto rumor de voces y de conciencias se levanta como un arco de alianza sobre la dulce y atarazada tierra de Francia. De la unidad del sentido nace la comunión telepática de las conciencias, y todos los hombres se comprenden religados en el milagro de una nueva Fe" (Valle-Inclán, 1976: 817).

\section{Referencias bibliográficas}

López-Casanova, A. (2000): “Valle-Inclán en Francia: un día de guerra”, en Santos Zas, M. (ed.): Valle-Inclán (1898-1998): Escenarios. Santiago de Compostela: Universidade de Santiago de Compostela.

Saint-Exupeéry, A. de (1990): Vuelo nocturno. Barcelona: Círculo de Lectores.

Valle-Inclán, R. M. del. (1976): “En la luz del día”, en Obras Escogidas, tomo 2. Madrid: Aguilar.

- (1976): “La media noche”, en Obras Escogidas, tomo 2. Madrid: Aguilar.

Villanueva, D. (1991): “La media noche de Valle-Inclán: análisis y suerte de su técnica narrativa”, en El polen de las ideas. Barcelona, PPU. 